\title{
Diagnóstico da Vegetação na Microbacia do Córrego Monjolo (Chapada dos Guimarães - MT) a partir do Método Verah
}

\section{Diagnosis of Vegetation in the Monjolo Stream Microbasin (Chapada dos Guimarães - MT) from the Verah Method}

\author{
Renata Freitag*a; Carla Regina Nascimento de Limab; Juliana Possavatz ${ }^{\mathrm{c}}$; Paulo Eduardo Reinach da Silva ${ }^{\mathrm{b}}$; \\ Oscar Carvalho Ramos ${ }^{\mathrm{b}}$; Selma Baia Batista ${ }^{\mathrm{c}}$
}
${ }^{a}$ Universidade do Estado de Mato Grosso, Programa de Pós-Graduação em Biodiversidade e Biotecnologia. MT, Brasil. bUniversidade Federal de Mato Grosso. MT, Brasil.
${ }^{\circ}$ Centro Universitário de Várzea Grande, MT, Brasil.
*E-mail: renatafreitagrh@gmail.com
Recebido em: 13/06/18; Aceito em: 29/11/18

\begin{abstract}
Resumo
A vegetação ciliar é extremamente importante para a proteção dos cursos de água, os efeitos causados pela eliminação desta vegetação podem ser: o assoreamento dos córregos e rios; deslocamento e desaparecimento de nascentes, da fauna aquática e terrestre; agravamento das secas e das cheias e escoamento direto de resíduos de áreas mais elevadas diretamente para a água. Nesse contexto, este trabalho decorreu da necessidade de ações urgentes voltadas ao controle da problemática ambiental constatada na microbacia do córrego Monjolo, no município de Chapada dos Guimarães, Estado de Mato Grosso. O objetivo do trabalho foi delimitar e caracterizar a vegetação existente na microbacia do córrego Monjolo, diagnosticar os problemas ocasionados pela supressão da vegetação e recomendar soluções. Essa microbacia é um importante curso de água para esse município, pois cerca de $60 \%$ da captação de água para o abastecimento urbano provém dele. A pesquisa utilizou o método VERAH ( $\mathrm{V}$ = Vegetação; $\mathrm{E}=$ Erosão; $\mathrm{R}$ = Resíduos; $\mathrm{A}$ = Água e $\mathrm{H}$ = Habitação). Inicialmente, ocorreu o reconhecimento da microbacia em campo, posteriormente, houve o levantamento e a identificação das espécies vegetais, e foram divididas em nativas do cerrado, exóticas e frutíferas/paisagísticas. Sete problemas relacionados à falta de vegetação foram apontados na área da microbacia, esses foram diagnosticados e, finalmente, elaborado o diagnóstico da microbacia. Existe a necessidade de um plano de ação que garanta a conservação desse recurso hídrico, algumas dessas ações começam pela recomposição da mata nativa, em alguns locais e elaboração de projetos educativos e de sensibilização, sobre a importância de conservar os recursos naturais.
\end{abstract}

Palavras-chave: Vegetação. Recursos Hídricos. Microbacia Urbana. Sustentabilidade.

\begin{abstract}
The riparian vegetation is extremely important for the protection of watercourses, the effects caused by its elimination can be: the silting of streams and rivers; displacement and disappearance of springs, aquatic and terrestrial fauna; aggravation of droughts and floods and direct disposal of waste from higher areas directly into the water. In this context, this work was due to the need for urgent actions aimed at controlling the environmental problems observed in the Monjolo stream watershed, in the municipality of Chapada dos Guimarães, Mato Grosso. The objective of this work was to delimit and characterize the existing vegetation in the Monjolo stream microbasin, to diagnose the problems caused by the suppression of vegetation and to recommend solutions. This microbasin is an important watercourse for this municipality, because about $60 \%$ of the water abstraction for urban supply comes from it. The research used the VERAH method $(V=V e g e t a t i o n, E=$ Erosion, $R=$ Residues, $A=$ Water and $H=$ Housing). Initially, the microbasin was detected in the field, later the plant species were collected and identified, and they were divided into cerrado, exotic and fruitful/landscape native species. Seven problems related to the lack of vegetation were pointed out in the area of the microbasin, these were diagnosed, and finally the microbasin diagnosis. There is a need for a plan of action that guarantees the conservation of this water resource, some of these actions begin by recomposing the native forest in some places and elaborating educational projects and raising awareness about the importance of conserving natural resources.
\end{abstract}

Keywords: Vegetation. Water Resources. Urban Microbasin. Sustainability.

\section{Introdução}

A vegetação tem um papel fundamental no balanço de energia e no fluxo de volumes de água, uma vez que a parcela inicial da precipitação é retida pela vegetação, quanto maior for a superfície de folhagem, maior a área de retenção da água durante a precipitação (BALBINOT et al., 2008). Sua importância não se limita apenas nisso, a vegetação também é extremamente importante na proteção dos cursos de água, e tem como uma de suas principais funções ecológicas a proteção do solo nas margens dos rios, impedindo o aporte de sedimentos ao leito, conservando assim a quantidade e qualidade da água. Dessa forma, a vegetação desempenha um papel estratégico, pois consegue isolar, estrategicamente, o curso de água dos terrenos mais elevados de uma microbacia, sendo eficaz na filtragem superficial (ALVES et al., 2014). Isto faz com que estes locais sejam protegidos por lei, constituindo-se em áreas de preservação permanente da flora e da fauna.

Neste contexto, o Cerrado é considerado um dos hotspots mundiais de biodiversidade (SILVA et al., 2016), e a segunda maior formação vegetal brasileira, ecossistema favorecido pela presença de diferentes paisagens e de três das maiores bacias hidrográficas da América do Sul, concentrando um terço da biodiversidade nacional e $5 \%$ da flora e da fauna mundial, sendo de 10 mil espécies vegetais, 837 aves e 161 mamíferos, 
tendo atualmente cerca de 20 milhões de ocupação humana, ocorrendo dessa forma uma alteração catastrófica no sistema ambiental deste bioma (CERRADO, 2019). Comparado com as savanas tropicais, o Cerrado tem maior diversidade de plantas, aproximadamente 12.000 espécies (SILVA et al., 2016).

A vegetação desse Bioma pode ser enquadrada em Formações Florestais (Mata Ciliar, Mata de Galeria, Mata Seca e Cerradão), Savânicas (Cerrado sentido restrito, Parque de Cerrado, Palmeiral e Vereda) e Campestres (Campo Sujo, Campo Rupestre e Campo Limpo) (CARVALHO, 2003). Contudo, cabe ressaltar que a recuperação de áreas degradadas de Cerrado é de suma importância para a manutenção desse bioma, que segundo estudos científicos poderá desaparecer em 30 anos, ficando restrito basicamente às unidades de conservação.

As áreas de Cerrado vêm sofrendo forte ameaça e as informações dos padrões de distribuição da vegetação nas áreas com grande diversidade se torna imprescindível. Diante desse cenário de uso intenso e degradação se encontra o córrego do Monjolo, o qual representa aproximadamente $60 \%$ da captação de água do município de Chapada dos Guimarães, devido a sua grande importância existe a necessidade de garantir a conservação desse recurso hídrico.

Sendo assim, esta pesquisa objetivou identificar, delimitar e caracterizar a vegetação da microbacia do córrego do Monjolo, bem como elaborar um mapa temático e quadro síntese de diagnóstico com sugestões de ações, que minimizem a degradação da microbacia. Este trabalho se faz necessário devido à situação de alta criticidade da microbacia do córrego do Monjolo, com necessidade de informações e ações urgentes voltadas ao controle da problemática ambiental, pois se trata de um dos pontos mais importante, no que se refere à preservação do Meio Ambiente, bem como nasce uma das nascentes de água potável que abastece a cidade de Chapada dos Guimarães.

\section{Material e Métodos}

Por meio de pesquisas realizadas pelo Programa de PósGraduação em Recursos Hídricos da Universidade Federal de Mato Grosso, tem se colocado em prática o método VERAH ( $\mathrm{V}$ = Vegetação; $\mathrm{E}=$ Erosão; $\mathrm{R}=$ Resíduos; $\mathrm{A}$ = Água e H = Habitação) nas principais microbacias urbanas próximas a capital do Estado, Cuiabá - MT. Esse método é considerado importante fonte interdisciplinar de informações para a educação e gestão ambiental (MENDONÇA et al., 2008; OLIVEIRA, 2016). Sua execução ocorre em quatro etapas principais: 1) preparação dos estudantes acerca do método VERAH e da microbacia selecionada; 2) realização em campo do diagnóstico (situação) da microbacia; 3 ) identificação dos cinco aspectos abordados pelo VERAH e suas correlações com o ambiente e desenvolvimento de recomendações para solucionar os problemas encontrados; 4) elaboração e entrega de relatório aos órgãos competentes e confecção de cartilha para público local (moradores), objetivando a implementação das recomendações e, consequentemente, conservação do meio ambiente e melhor qualidade de vida para a população.

\section{1 Área de estudo}

O município de Chapada dos Guimarães se localiza na Região Central da América do Sul, no Estado de Mato Grosso, aproximadamente a $60 \mathrm{~km}$ da capital Cuiabá, mais precisamente entre as coordenadas geográficas $15^{\circ} 27^{\prime}$ 16.69 " S e $55^{\circ} 43$ ' 58.99 " W. O objeto deste estudo foi a microbacia do córrego Monjolo, com uma área de 203 ha. $\mathrm{O}$ córrego Monjolo é afluente do Rio Cachoeirinha, que ao se unir com o Rio Lagoinha forma o rio Quilombo que, por sua vez, é afluente do rio da Casca, este afluente do rio Manso, sendo afluente do rio Cuiabá, que por sua vez é afluente do rio Paraguai, fazendo parte da grande bacia do Prata (ROSS, 2014). O relevo da microbacia do Monjolo se apresenta em sua seção de maior altitude, aproximadamente 834 metros de elevação, chegando em sua seção mais baixa a 760 metros acima do nível do mar. Este relevo confere para a microbacia uma conformação de vale (Figura 1).

Figura 1 - Localização da microbacia do Córrego Monjolo com fluxos preferenciais de escoamento superficial delimitado por curvas de nível.

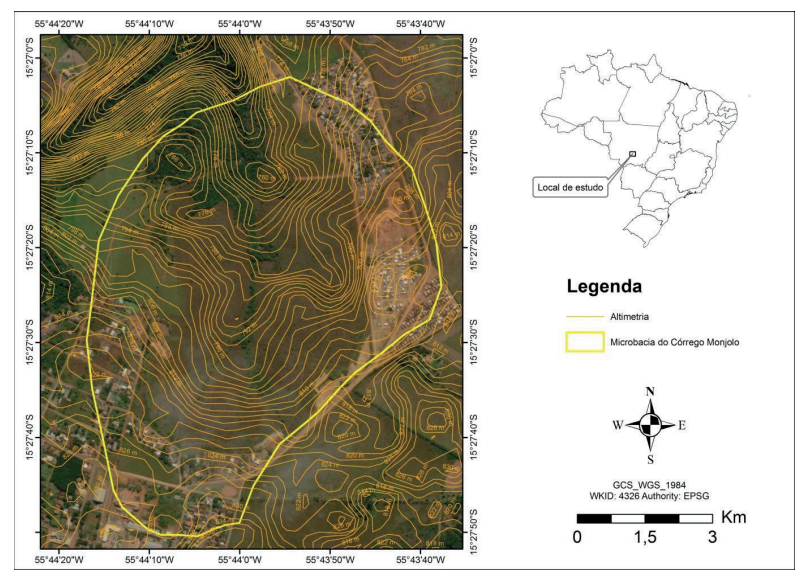

Fonte: Ramos (2019).

A área pertence à Bacia Sedimentar do Paraná (Domínio Morfoestrutural) geomorfologicamente na Região do Planalto dos Guimarães, tendo como unidade morfológica o Planalto Conservado (ROSS, 2014). Geologicamente é sustentada por rochas sedimentares das formações Furnas e Ponta Grossa, parcialmente recobertas por sedimentos terciário/ quaternários detrito-lateríticos (SALOMÃO et al., 2012). Os solos são predominantemente rasos, tendo em vista a ocorrência de rocha e couraça ferruginosa subaflorantes, mas com ocorrências localizadas de solos profundos (Latossolos e Neossolos Quartzarênicos) e plintossolos (ROSS, 2014).

$\mathrm{O}$ município de Chapada dos Guimarães pertence à Província Hidrogeológica da Bacia do Paraná que abrange a Região Sul e Sudeste do Estado. A Unidade Geoambiental 
Chapadas em solos argilo-arenosos consiste de terrenos bem drenados, com alta capacidade de carga e de altas taxas de infiltração dos solos, em zona de recarga dos aquíferos, e alto potencial hidrogeológico em direção ao interior do planalto (SALOMÃO et al., 2012).

Apresenta, portanto, solos friáveis e muito permeáveis, com alta erodibilidade em textura de areia fina. Assim, apresenta uma alta vulnerabilidade natural dos aquíferos (ROSS, 2014). Consiste de terrenos de baixa fertilidade natural com restrições para disposição de resíduos sólidos. No planalto dos Guimarães, os principais impactos estão relacionados às atividades humanas.

A vegetação original aos arredores da microbacia do Monjolo é composta por Cerrado, sendo em grande parte, substituída por zonas de pecuária e a ocupação urbana (SILVA et al., 2016). Cabe ressaltar que a substituição da vegetação natural, intensificada pela pecuária e habitação, nos últimos anos, provocou a ocorrência de fenômenos erosivos e de assoreamento, geralmente, sendo muito intensos nas cabeceiras de drenagens.

\subsection{Procedimentos de campo}

Realizou-se o reconhecimento geral da microbacia em outubro de 2011. In situ trabalhou-se no levantamento para o reconhecimento e identificação das espécies, sendo que para algumas espécies foi necessária a organização de exsicata para que fossem mantidas as características originais, e transportadas ao Herbário Central da Universidade Federal de Mato Grosso, em que foram identificadas pelos profissionais capacitados.
A identificação ocorreu em toda a bacia, e foram divididas em espécies nativas do cerrado, espécies exóticas e espécies frutíferas/paisagísticas. Posteriormente, realizou-se a confecção de um gráfico demonstrando a cobertura vegetal nos três bairros, que cercam a microbacia (Bairro São Sebastião, Bairro Sol Nascente, Cohab Vista Alegre), respeitando as porcentagens de $0-20$, de $20-40$, de $40-60$, de $60-80$, e de $80-100 \%$. Todos os objetivos propostos pela pesquisa foram cumpridos respeitando as bibliografias direcionadas ao tema e legislações específicas.

\subsection{Exposição dos resultados}

Apresentaram-se todos os resultados da pesquisa à comunidade em audiência pública na Câmara Municipal do Município de Chapada dos Guimarães. Na exposição, abordou-se o assunto com linguagem de acordo com o públicoalvo e, de forma didática, para a compreensão de todos os participantes, entre eles membros do Poder Legislativo e comunidade em geral.

\section{Resultados e Discussão}

\subsection{Diagnóstico da área}

No levantamento florístico realizado na microbacia do córrego Monjolo, verificou-se a presença ou eventuais ausências dos estratos arbóreos, arbustivos e herbáceos, ressaltando nas atividades antrópicas presentes na microbacia, contudo não foi contabilizado o número desses indivíduos. Identificaram-se 33 espécies vegetais nativas distribuídas em 22 famílias, sendo a Fabaceae com maior representatividade (Quadro 1).

Quadro 1 - Relação de espécies nativas encontradas na microbacia do córrego Monjolo, Chapada dos Guimarães - MT. Continua...

\begin{tabular}{|c|c|c|c|}
\hline Nome científico & Autor & Família & Nome popular \\
\hline Anadenanthera colubrina & (Vell.) Brenan & Fabaceae & Angico \\
\hline Siparuna guianensis & Aubl. & Siparunaceae & Negramina \\
\hline Doliocarpus dentatus & (Aubl.) Standl. & Dilleniaceae & Cipó-Vermelho \\
\hline Vochysia haenkeana & Mart. & Vochysiaceae & Cambará Amarelo \\
\hline Vochysia divergens & Pohl & Vochysiaceae & Cambará Preto \\
\hline Machaerium paraguariense & Hassl. & Fabaceae & Jacaranda \\
\hline Erythroxylum deciduum & A.St.-Hil. & Erythroxylaceae & Marmelada \\
\hline Bixa orellana & L. & Bixaceae & Urucum \\
\hline Sorocea guilleminiana & Gaudich. & Moraceae & Cancerosa \\
\hline Rhynchospora globosa & (Kunth) Roem. \& Schult. & Cyperaceae & Capim \\
\hline Trema micrantha & (L.) Blume & Cannabaceae & Piriquiteira \\
\hline Emmotum nitens & (Benth.) Miers & Icacinaceae & Carvalho \\
\hline Sclerolobium aureum & Hassl. & Fabaceae & Justaconta \\
\hline Piper cuyabanum & C. DC. & Piperaceae & Jaborandi \\
\hline Cecropia hololeuca & Miq. & Urticaceae & Embaúba \\
\hline Solanum lycocarpum & A. St.-Hil. & Solanaceae & Lobeira \\
\hline Laportea aestuans & (L.) Chew & Urticaceae & Urtiga \\
\hline Mimosa pudica & L. & Fabaceae & Dorme-dorme \\
\hline Tibouchina granulosa & (Desr.) Cogn. & Melastomataceae & Quaresmeira \\
\hline Mauritia flexuosa & L.f. & Arecaceae & Buriti \\
\hline Attalea speciosa & Mart. & Arecaceae & Babaçu \\
\hline Anacardium humile & A.St.-Hil. & Anacardiaceae & Cajuzinho do cerrado \\
\hline Margyricarpus pinnatus & Lam. & Rosaceae & Fruta de perdiz \\
\hline
\end{tabular}




\begin{tabular}{|c|c|c|c|}
\hline \multicolumn{1}{|c|}{ Continuação. } \\
\hline Nome científico & Autor & Família & Nome popular \\
\hline Bauhinia variegata & L. & Fabaceae & Pata de vaca \\
\hline Leucaena leucocephala & (Lam.) de Wit & Asteraceae & Assa-peixe \\
\hline Cabobanthus polysphaerus & (Baker) H.Rob. & Dilleniaceae & Lixeira \\
\hline Curatella americana & L. & Erythroxylaceae & Mamona \\
\hline Erythroxylum deciduum & A.St.-Hil. & Chrysobalanaceae & Oiti \\
\hline Hirtella glandulosa & Spreng. & Dilleniaceae & Lixeira \\
\hline Curatella americana & L. & Rubiaceae & Escorrega macaco \\
\hline Calycophyllum spruceanum & (Benth.) Hook.f. & Bignoniaceae & Boca de sapo \\
\hline Jacaranda cuspidifolia & Mart. & Phyllanthaceae & Figueirinha \\
\hline Margaritaria nobilis & L.f. &
\end{tabular}

Fonte: Dados da pesquisa.

Também foram observadas algumas espécies de plantas exóticas, frutíferas, paisagísticas e medicinais nos bairros residenciais existentes dentro microbacia. As espécies que mais encontradas foram as popularmente conhecidas como: Mamona, Coco, Rosas, Flores diversas, Pingo de ouro, Manga, Amora, Pitanga, Jabuticaba, Goiaba, Ingá, Mamão, Grama de jardim, Erva cidreira, Caferana, Boldo, Babosa e Pinheiro.

Quanto à cobertura vegetal do solo na microbacia, os resultados indicam que o bairro com maior cobertura vegetal é o Sol Nascente, aproximadamente $70 \%$, encontrando-se bem estruturado em comparação com os demais. Seguido por São Sebastião, que está entre 20 e 40\%. E em menor quantidade de vegetação está o bairro Vista Alegre, com no máximo $20 \%$ de cobertura, esse resultado pode ser devido à péssima qualidade de infraestrutura e por possuir uma população de baixa renda

\subsection{Problemas encontrados}

Ponto de Captação do Córrego Monjolo: localizado em área de preservação permanente (APP) de acordo com a Legislação Ambiental Federal Lei $\mathrm{n}^{\circ}$ 12.651/2012 (BRASIL, 2012). A fitofisionomia encontrada no local é do tipo cerradão, pois possui árvores de grande porte e alta densidade. Encontraram-se espécies como Trema micrantha; Emmotum nitens; Tachigali aurea e Piper cuyabano. Cabe ressaltar que segundo a Resolução 369/2006 do CONAMA (BRASIL, 2006), a casa de máquinas para captação de água de consumo humano deve ser construída após a APP, salvo em locais nos quais não há espaço suficiente para tal, o que não é o caso da área em questão. $\mathrm{O}$ equipamento para bombear a água pode causar contaminação, através dos óleos utilizados em sua manutenção. Portanto, recomenda-se providenciar a correta localização da casa de máquinas, conforme orientações do órgão ambiental responsável.

Área de Pecuária: verifica-se que este local está bem próximo das barreiras de contenção, sendo delimitado por meio de cercas da área de campo sujo. Há algumas árvores de grande porte em pontos esparsos. O pisoteio do gado promove a formação de sulcos, compactação do solo e, consequentemente, a diminuição da capacidade de recarga do aquífero, acarretando no aumento do escoamento superficial, causando assoreamento do córrego, além de provocar a contaminação do manancial por meio das fezes dos animais. Acredita-se que é necessária a remoção da pecuária de dentro da área de microbacia para um local apropriado a tal atividade.

Plantas Exóticas: encontrou-se na microbacia a Brachiaria $s p$. como a espécie exótica mais abundante. Essa espécie, provavelmente, foi introduzida na área para pastagem, contudo, ela pode se naturalizar e dispersar alterando o ecossistema, uma vez que afeta o funcionamento natural da área e compete com as plantas nativas. Uma sugestão encontrada seria a plantação de mudas de espécies nativas, o que já vem sendo feito pela gestão do município nas áreas próximas às barragens, nas quais havia a Brachiaria sp. Uma espécie exótica que chamou a atenção foram alguns pinheiros (nativos da Região Sul do país) na área urbana da microbacia, porém por ser em pequena quantidade e apresentar certa harmonia para a paisagem do local, não representa problema nenhum para esse ambiente.

Rede de Drenagem Pluvial: construção da rede de drenagem pluvial no bairro Sol Nascente e pavimentação asfáltica. O problema é a redução da infiltração e aumento da taxa de escoamento superficial, que será conduzida rapidamente para os fundos de vales. A caixa de dissipação da água pluvial se encontra com uma grande quantidade de sedimentos. Recomenda-se a limpeza periódica da caixa de dissipação, a construção de bacias de infiltração, obras de disciplinamento e de dissipação da energia destas águas.

Solo Exposto: localizado principalmente no bairro Vista Alegre, por se tratar de uma antiga área de empréstimo de cascalho, sendo que a empresa que fazia uso desta era responsável por seu futuro reflorestamento, mas não o fez. A não recuperação da área de empréstimo favoreceu a formação de um depósito de lixo irregular. O solo se encontra lixiviado, promovendo assim o carreamento de sedimentos para o fundo da microbacia, causando influência no ponto de captação de água da cidade. Considerando que as ações devem ser planejadas, projetadas e realizadas para recuperar o uso original, ou para permitir novos usos, cujas características originais sofreram alterações, recomenda-se a revegetação imediata da área, tendo ainda como sugestão a criação de um "parque ou praça", pois ao mesmo tempo em que a área será revitalizada, também pode ser ofertado à população um ambiente de lazer e bem-estar, com realização de atividades físicas. Acredita-se que tal ação é de grande importância, uma 
vez que a população local é de baixa renda.

Erosão e Assoreamento: encontra-se dentro da área destinada para a pecuária alguns sulcos evoluindo para ravina, que devido ao relevo local têm como destino o ponto de captação de água do Córrego Monjolo. O relevo da microbacia apresenta de amplitude altimétrica de 74 metros entre a maior altitude à montante e a menor altitude à jusante da microbacia. $\mathrm{O}$ relevo mais acidentado é predominante na região, dessa forma, maior será o escoamento superficial da água das chuvas, logo, menor infiltração, podendo provocar erosões. Essa problemática, somada ao uso inadequado do solo, pode provocar assoreamento do córrego e alterações na qualidade da água usada para o abastecimento público do município de Chapada dos Guimarães. Dessa forma, reitera-se que é necessário o isolamento da área, permitindo a regeneração natural da vegetação e realização de plantio direto de mudas nativas do cerrado.

Tratamento de efluentes: o tipo de solo característico nas proximidades do bairro localizado no sentido Nordeste da bacia do córrego Monjolo (Sol Nascente) é latossolo, propício à infiltração. Neste bairro, o sistema de tratamento de efluente é por fossa séptica. Portanto, verifica-se a real e urgente necessidade de implantação de um sistema de esgotamento sanitário na microbacia, a fim de coletar e tratar os efluentes gerados pela população e evitar a poluição dos recursos hídricos subterrâneos e superficiais. Visando a qualidade das águas subterrâneas e superficiais é importante fazer o cadastramento de poços existentes na região.

\subsection{Mapa temático}

$\mathrm{Na}$ atividade de campo foram coletados pontos de GPS (Global Positioning System), realizada a identificação fitofisionômica da vegetação do cerrado e, por meio de imagem de satélite, foi possível a elaboração de um mapa da classificação vegetacional da área de estudo. Verifica-se que a microbacia do córrego Monjolo apresenta fitofisionomias diferentes, o cerradão, na região mais próxima das cabeceiras compreendendo a mata ciliar e a mata de galeria; seguido pelo campo sujo; e por poucos espaços constituídos de campo limpo (Figura 2).

Figura 2 - Classificação Vegetacional do Córrego Monjolo.

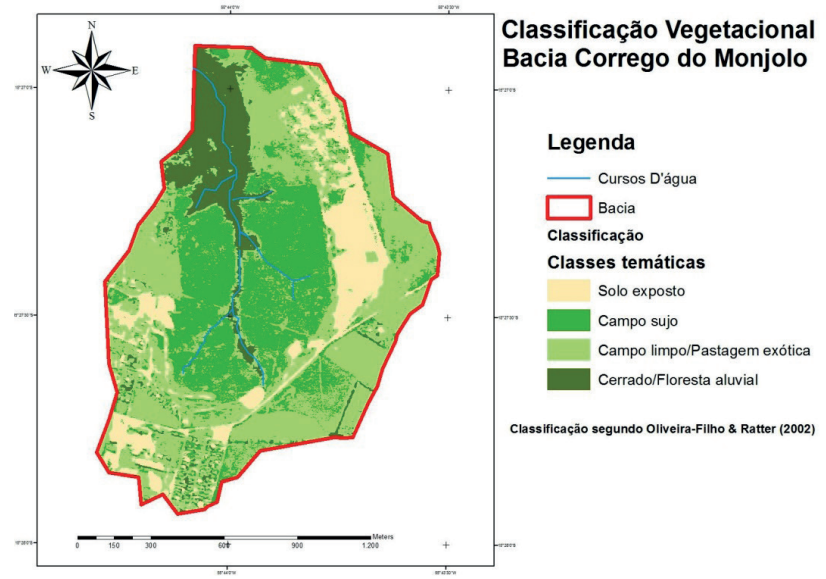

Fonte: Santos (2011).
As áreas de nascentes dos rios, especialmente quando degradadas, apresentam elevada vulnerabilidade à contaminação dos recursos hídricos, principalmente, pelo processo de escoamento superficial, devido aos processos erosivos e ausência de barreiras naturais de proteção. A região de Chapada dos Guimarães compreende áreas de risco geológico não favorável para a ocupação urbana, as quais devem ser destinadas à preservação, contudo, o uso eventual e localizado pode ser admitido, desde que autorizado pela Administração Pública por interesse social e com prévio estudo de impacto (SALOMÃO et al., 2012).

Os efeitos causados pela eliminação da mata ciliar podem ser o assoreamento dos córregos e rios; deslocamento e desaparecimento de nascentes; desaparecimento da fauna aquática e terrestre; agravamento das secas e das cheias e escoamento direto de resíduos de agrotóxicos das áreas agrícolas mais elevadas diretamente para a água (TRES et al., 2007). Uma das formas de evitar a contaminação pelo escoamento superficial e iniciar o processo de recuperação dessas áreas é a implementação de faixas de contenção, como forma de mitigação (FREITAG et al., 2014). Os processos de mitigação apresentam como principal objetivo à redução do risco de contaminação dos recursos hídricos, evitando assim a entrada de contaminantes.

Aestratégia de recuperar locais degradados, principalmente, aqueles relacionados com Áreas de Preservação Permanente, visa em última instância, restituir a cobertura vegetal que exerce um importante papel na proteção dos recursos hídricos e dos solos, e na estabilização de terrenos, reduzindo perdas de água por evaporação, elevando a retenção de água e aumentando o teor de matéria orgânica, melhorando, assim, a resistência do solo à erosão pela maior estabilidade dos agregados (BALBINOT et al., 2008), proporciona, ainda, condições básicas de sobrevivência para muitos animais da fauna silvestre, fornecendo recurso alimentar, abrigo, refúgio, condições para reproduzir e ainda incrementa o fluxo gênico, e principalmente propicia a qualidade da água (TRES, 2007).

A recuperação ambiental representa o retorno de uma área que sofreu degradação a uma forma e utilização, de acordo com um plano preestabelecido para o uso do solo local, de modo a se alcançar uma situação estável, na qual estejam presentes as condições mínimas para que um novo equilíbrio dinâmico se processe (IBAMA, 1990). Para atingir o objetivo da restauração, que é o de "promover uma nova dinâmica de sucessão ecológica, onde ocorram níveis intensos de interação entre produtores, consumidores e de decompositores, em um ciclo contínuo de mortes e nascimentos" (TRES, 2007), é recomendada a utilização de técnicas de nucleação (FREITAG et al., 2013; FREITAG et al., 2018). As atividades de restauração, baseadas no processo ecológico de nucleação, são propostas por Reis et al., (2003) como "Técnicas nucleadoras de restauração".

De acordo com os autores supracitados, as principais 
técnicas nucleadoras estão: 1) plantio mecanizado de árvores é a técnica comumente utilizada para plantio de grãos, no qual a terra é previamente preparada com trator e grade. Para o plantio podem ser utilizadas plantadeiras de precisão e lançadeiras Vincón; 2) a semeadura direta é o processo pelo qual as sementes das espécies escolhidas são semeadas diretamente no campo, ou seja, no solo; 3) poleiros artificiais têm sido apontados como um método nucleador de baixo custo para a restauração, confeccionado com galhos secos, de bambu e de eucalipto ou plantio de árvores de rápido crescimento, atraindo a avifauna, que promove a disseminação das sementes; 4) o processo de transposição de solo também é conhecido como transposição do banco de sementes, promove a restituição do banco de sementes e biota do solo.

Porém para se realizar uma restauração bem-sucedida, antes de realizar o plantio com técnicas de nucleação é recomendado o uso das leguminosas, que apresentam elevado potencial de fixação biológica de nitrogênio (FBN) e de produção de biomassa, como adubos verdes, além de proporcionar economia com fertilizantes, contribui para o manejo ecológico (ESPINDOLA et al., 2006). Deste modo, haverá menos mortes de mudas e as mesmas terão um bom desenvolvimento.

As espécies mais usadas em recuperação são a Crotalaria juncea e Crotalaria ochroleuca, porque são de rápido crescimento, promovem a recomposição orgânica e mineral do solo, têm alto poder de fixação de nitrogênio, limitam o crescimento de nematoides parasitas, além de auxiliar na rotação de culturas (REIS et. al., 2003). A leguminosa Cajanus cajan, feijão guandu anão, é de fácil penetração em solos compactados o que irá auxiliar no processo de infiltração da água no solo. O feijão-de-porco, Canavalia ensiformis, também é de rápido crescimento e contribui com o aumento da massa vegetal. São espécies adequadas para a microbacia no plantio inicial, já que o solo se encontra compactado e pobre em nutrientes e biomassa.

As leguminosas têm auxílio extra na captura de nitrogênio $\left(\mathrm{N}_{2}\right)$, pois parte do $\mathrm{N}_{2}$ incorporado no tecido vegetal é fixado por meio de simbiose (BECHARA et al., 2007). As bactérias se associam às raízes das leguminosas e atuam na fixação de nitrogênio atmosférico; em troca, as leguminosas disponibilizam o carboidrato que os decompositores utilizam para o seu crescimento. As leguminosas, também fazem a imobilização temporária de nitrogênio em sua biomassa. Dessa forma, essas plantas têm poder de tornar o solo mais fértil, logo, um ambiente mais propício para o desenvolvimento das espécies nativas.

A supressão ou a ausência da cobertura vegetal nas microbacias altera as condições locais, podendo na maioria dos casos gerar desequilíbrio ecológico (FREITAG et al., 2018). Assim, acredita-se que a vegetação deve ser mantida, respeitando as características de cada local, uma vez que a existência de vegetação contribui para proteger os cursos de água, os serviços ecossistêmicos e todos aqueles que, de maneira direta ou indireta, se beneficiam deles. Crê-se que a educação ambiental é melhor caminho para que as pessoas aprendam como o meio ambiente funciona, a interdependência e como se tornar sustentáveis.

\section{Conclusão}

Concluiu-se que a microbacia do Córrego Monjolo possui vegetação suprimida, além de muitos outros problemas ambientais decorrentes da pouca ou ausente vegetação.

Verificou-se que a presença da vegetação tem grande importância na preservação da microbacia, logo, na manutenção e na distribuição da água.

A utilização do método VERAH facilitou a detecção de um conjunto de problemas ambientais ocasionados pelo mau uso e ocupação do solo e ambiente como um todo. Além de permitir propor orientações ambientais e comportamentais, a fim de recuperar o ambiente comum ao uso de todos.

\section{Referências}

ALVES, M.A.S. et al. Levantamento Florístico na Microbacia do Córrego Quineira, Município de Chapada dos Guimarães - MT. Centro Cient. Conhecer, v.10, n.19, p. 2943-2954, 2014

BALBINOT, E. et al. O papel da floresta no ciclo hidrológico em bacias hidrográficas. Ambiência, v.4, n.1, p.131-149, 2008.

BECHARA, F.C. et al. Unidades Demonstrativas de Restauração Ecológica através de Técnicas Nucleadoras de Biodiversidade. Rev. Bras. Biociê., v.5, p.9-11, 2007.

BRASIL. Lei $\mathrm{N}^{\mathrm{o}} 12.651$, de 25 de maio de 2012. Novo Código Florestal. 2012.

BRASIL. CONAMA - Conselho Nacional do Meio Ambiente: Resolução n 369, 2006.

CARVALHO, P.E.R. Espécies Arbóreas brasileiras. EMBRAPA informação tecnológica, Colombo: Embrapa Florestas, 2003.

ESPINDOLA, J.A. et al. Decomposição e liberação de nutrientes acumulados em leguminosas herbáceas perenes consorciadas com bananeira. Rev. Bras. Ciênc. Solo, v.30, p.321-328, 2006.

FREITAG, R. et al. Técnicas nucleadoras e adubação verde em unidades demonstrativas de restauração ecológica. Rev Ciênc. Agrárias, v.41, n.1, p. 56-71, 2018.

FREITAG, R.; RIBEIRO, R. Q.; BONINI, B. Diagnóstico ambiental e recomendações para recuperação de uma área degradada por voçoroca no Córrego Cabeceira Grande, Campo Verde - MT. Centro Cientifico Conhecer, v.10, n.19, p. 20782090, 2014.

FREITAG, R.; SILVA, N. M.; VECCHIATO, A. B. Técnicas de nucleação como estratégia de recuperação e valoração ambiental de áreas degradadas situadas no Alto Rio São Lourenço, Campo Verde-MT. Rev. UNIARA, v.16, n.2, 2013.

IBAMA. Instituto Brasileiro do Meio Ambiente e dos Recursos Naturais Renováveis. Manual de Recuperação de Áreas Degradadas pela Mineração: Técnicas de Revegetação. Brasília: IBAMA, 1990.

MENDONÇA, R.C. et al. VERAH - Diagnóstico Ambiental de Microbacia. Cuiabá: UFMT, 2008.

OLIVEIRA, A.M.S. O Método VERAH. São Paulo: Ícone. São Paulo, 2016. 
CERRADO. Conhecendo o Cerrado. Disponível em: https:// www.todoestudo.com.br/geografia/cerrado. Acesso em: 1 fev. 2019.

REIS, A. et al. Restauração de áreas degradadas: a nucleação como base para incrementar os processos sucessionais. Nat Conserv., v.1, n.1, p.28-36, 2003.

ROSS, J.L.S. Chapada dos Guimarães: borda da bacia do Paraná Rev. Depart. Geogr. USP, v.28, p.180-197, 2014.

SALOMÃO, F.X.T.; MADRUGA, E.L.; MIGLIORINI, R.B Carta geotécnica do perímetro urbano da Chapada dos Guimarães: subsídios ao plano diretor. Geologia USP, v.12, n.1, p.5-15, 2012.

SILVA, R.A. et al. Fitossociologia da comunidade arbórea de cerrado sensu stricto do Parque Nacional da Chapada dos Guimarães. Nativa, v.4, n.2, p. 82-86, 2016.

TRES, D.R. et al. Poleiros artificiais e transposição de solo para a restauração nucleadora em áreas ciliares. Rev. Bras. Biociênc., v.5, p.312-314, 2007.

TUCCI, C.E. M.; SILVEIRA, A.L.L. Gerenciamento da drenagem urbana. 2001. Disponível em:http://galileu.iph.ufrgs.br/joel/ iph014/Gerdre.pdf. Acesso em: 30 dez. 2018. 